\title{
SOME METHODS FOR WASHING SPERMATOZOA FROM BULL, BOAR AND RAM: A COMPARISON USING BIOCHEMICAL AND OTHER CRITERIA
}

\author{
R. A. P. HARRISON AND I. G. WHITE* \\ A.R.C. Unit of Reproductive Physiology and Biochemistry, Cambridge $\dagger$
}

(Received 27th April 1971, accepted 12th May 1971)

\begin{abstract}
Summary. A study was made of three methods of washing bull, boar and ram spermatozoa, using as criteria contamination with free-lying cytoplasmic droplets, sperm motility and leakage of glucose-phosphate isomerase and hexokinase into the medium. The methods used were: washing in a Ringer-fructose-phosphate medium, washing in a hypoosmotic phosphate medium and washing with balanced media in the cold after slow cooling and storage overnight at $4^{\circ} \mathrm{C}$ in a milk diluent. Only by using the last method was it possible to remove adequately the freelying cytoplasmic droplets; this method also caused least damage to the sperm suspensions.

The problems of washing spermatozoa with respect to cell damage and leakage of enzymes are discussed in the light of the present findings. The evidence suggests that glucose-phosphate isomerase and hexokinase leak from the cytoplasmic droplets as well as from the spermatozoa during washing. Hypo-osmotic media appear to cause an immediate and marked release of these enzymes from the droplets.
\end{abstract}

\section{INTRODUCTION}

In addition to spermatozoa, semen may contain other particulate matter, e.g. epithelial cells and débris, sperm fragments, lipid globules and free cytoplasmic droplets. The last are attached to spermatozoa on leaving the testis but are shed after passage through the epididymis, and are regularly found in ejaculates from mature rams, bulls and boars (Dott \& Dingle, 1968). Both the seminal plasma and extraneous particulate matter are undesirable contaminants of sperm preparations for critical biochemical experiments: the ideal goal is a pure population of undamaged spermatozoa.

Many procedures have been published for washing spermatozoa free of seminal plasma (e.g. Baker, 1931; White, 1953; Salisbury \& Graves, 1963; Mann, 1964; Rikmenspoel, 1965; Hoskins \& Patterson, 1967; Wales \& Humphries, 1969). In the past, however, little attempt has been made to wash the spermatozoa free of cytoplasmic droplets.

The problem is complex. When washed at room temperature in a physiological medium, a relatively great centrifugal force is necessary to sediment the

* Present address: Department of Veterinary Physiology, University of Sydney, Sydney, Australia.

$\dagger$ Postal address: Animal Research Station, 307 Huntingdon Road, Cambridge CB3 0JQ. 
highly motile spermatozoa and many droplets will be sedimented with them; furthermore, the pellet will be tightly packed and efforts to resuspend the spermatozoa may damage them. If the centrifugal force is reduced, fewer droplets will be sedimented with the spermatozoa but a large proportion of the more highly motile cells will be left in the supernatant.

Washing entails another risk: unless some high molecular weight-protective agent is added to the wash fluid, spermatozoa may suffer 'the dilution effect' which is characterized by irreversible loss of viability (see Bishop \& Walton, 1960; Mann, 1964). Immobilization of spermatozoa before centrifugation and washing makes it possible to sediment the spermatozoa by low-speed centrifugation. Under these conditions, cytoplasmic droplets mostly remain in suspension and the sperm pellet is easily resuspended. But methods of immobilization may be detrimental, e.g. cooling can cause cold-shock (Bishop \& Walton, 1960; Mann, 1964), and chemical immobilization may permanently alter sperm constituents.

The aim of this study was to compare three ways of washing spermatozoa using various criteria and to highlight some of the problems which arise.

\section{MATERIALS AND METHODS}

\section{Semen}

Semen was obtained from boars of proven fertility by manual collection using a 'dummy sow', and was then strained through cheese-cloth to remove the gel. Single collections (normally a double ejaculate) were used for each experiment.

Ram semen was collected between November and March using an artificial vagina. A sample from the pooled ejaculates of twenty rams was used for each experiment.

Bull semen was collected using an artificial vagina and the pooled ejaculates from between two and four bulls were used for each experiment; a different combination of bulls was used each time and at least twelve bulls were involved (all were taking part in a progeny-testing scheme).

All semen samples were of high motility. They were kept at $20^{\circ} \mathrm{C}$ until needed and were used within $1 \mathrm{hr}$ of collection.

\section{Washing methods}

A general flow sheet is shown in Text-fig. 1 and details of the centrifuging in Table 1. The three methods of washing which were compared were:

Ringer method. (The normal washing procedure at room temperature in a Krebs-Ringer-fructose-phosphate medium-see Mann, 1964.) Bull and boar semen were spun directly and ram semen was spun after diluting with three volumes of the Ringer solution. The supernatant was removed and the pellet resuspended gently in Krebs-Ringer-fructose-phosphate medium (RFP). The suspension was then respun and the supernatant removed. The procedure was repeated, and the spermatozoa finally resuspended to a convenient concentration. The density of the sperm suspensions during washing was between 0.3 and $0.7 \times 10^{9}$ cells $/ \mathrm{ml}$, and that of the final preparations between 0.7 and $2.0 \times 10^{9}$ cells $/ \mathrm{ml}$. 
Hypo-osmotic method. (Irreversible immobilization of the spermatozoa by hypo-osmotic shock - see Quinn \& White, 1969-followed by washing and slow centrifugation at room temperature.) Bull and boar semen were spun directly and ram semen spun after diluting with three volumes of hypo-osmotic phosphate medium (HOP) consisting of $50 \mathrm{~mm}$-potassium phosphate buffer, $5 \mathrm{~mm}-2$ mercaptoethanol, $5 \mathrm{~mm}$-EDTA, $\mathrm{pH} \mathrm{7.0}$. The supernatant was removed and the pellet was gently resuspended in HOP; the suspension was then respun, and the

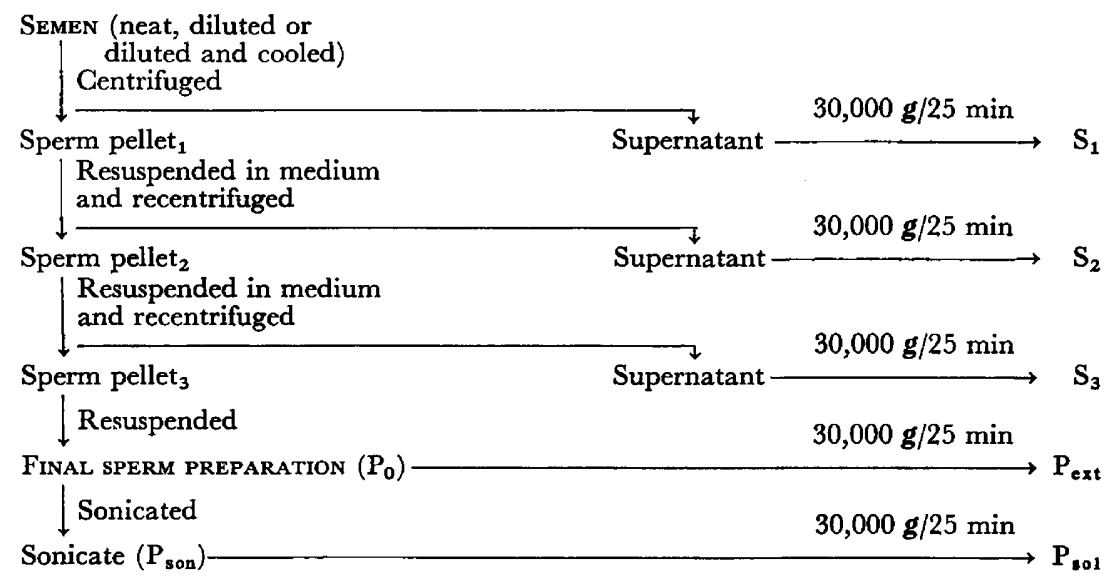

TEXT-FIG. 1. Diagram illustrating washing procedure for semen, fractions obtained and designations of fractions. For details of centrifuging, see Table 1 .

TABLE 1

SPEEDS AND DURATION OF GENTRIFUGATION FOR WASHING SPERMATOZOA

\begin{tabular}{l|l|c|c}
\hline \multicolumn{1}{c|}{ Method } & \multicolumn{1}{|c|}{ Species } & First spin & Second and third spins \\
\cline { 2 - 3 } Ringer & Bull and ram & $2500 \mathrm{~g}$ for $17 \mathrm{~min}$ & $2000 \mathrm{~g}$ for $12 \mathrm{~min}$ \\
& Boar & $1000 \mathrm{~g}$ for $17 \mathrm{~min}$ & $600 \mathrm{~g}$ for $12 \mathrm{~min}$ \\
Hypo-osmotic & Bull and ram & $2500 \mathrm{~g}$ for $17 \mathrm{~min}$ & $600 \mathrm{~g}$ for $12 \mathrm{~min}$ \\
Cooling & Boar & $1000 \mathrm{~g}$ for $17 \mathrm{~min}$ & $600 \mathrm{~g}$ for $12 \mathrm{~min}$ \\
& All three & $600 \mathrm{~g}$ for $15 \mathrm{~min}$ & $600 \mathrm{~g}$ for $15 \mathrm{~min}$ \\
\hline
\end{tabular}

An M.S.E. Super Minor centrifuge was used with a swing-out head and $50-\mathrm{ml}$ tubes; all R.C.F. values are calculated to the bottom of the tube.

supernatant removed. The procedure was repeated, and the spermatozoa finally resuspended to a convenient concentration. The densities of the sperm suspensions were similar to those in Method 1.

Cooling method. (Reversible immobilization by cooling in a protective medium to avoid cold shock, followed by washing and slow centrifugation at $4^{\circ} \mathrm{C}$.) Boar semen was concentrated by centrifugation in the large angle head of an M.S.E. High Speed refrigerated centrifuge, at $1500 \mathrm{rev} . / \mathrm{min}$ (about $360 \mathrm{~g}$ ) for $15 \mathrm{~min}$ at room temperature. The loose pellet was gently resuspended in a small volume of the seminal plasma. The concentrated boar semen, or neat ram or 
bull semen was extended with a milk diluent, modified from Lapwood's recipe (see below) to a final density of 1 to $2 \times 10^{8}$ spermatozoa $/ \mathrm{ml}$. This was then cooled slowly from room temperature down to $4^{\circ} \mathrm{C}$, by immersing the container of the diluted semen in a water-jacket at the same temperature (total volume of water-jacket + diluted semen was 600 to $1000 \mathrm{ml}$ ) and leaving overnight in the cold room. This gave a cooling curve with an initial cooling rate of less than $0 \cdot 15^{\circ} \mathrm{C} / \mathrm{min}$, which is slow enough to avoid cold shock (du Mesnil du Buisson, 1956). Next morning, the suspension was gently but thoroughly resuspended and washed twice and finally resuspended as above, using as wash medium a solution containing $200 \mathrm{~mm}$-sucrose, $19 \mathrm{~mm}-\mathrm{NaH}_{2} \mathrm{PO}_{2}, 31 \mathrm{~mm}-\mathrm{NaCl}, 5 \mathrm{~mm}$ $\mathrm{KOH}$, brought to $\mathrm{pH} 7.0$ by adding $\mathrm{NaOH}$. Other wash media were also tested and were found to be equally effective, provided they were iso- or slightly hypo-osmotic. All washing operations were carried out at $4^{\circ} \mathrm{C}$.

\section{Preparation of milk diluent (modified from Lapwood, 1968)}

One pint of fresh milk was centrifuged at $4^{\circ} \mathrm{C}$ for $45 \mathrm{~min}$ at $6000 \mathrm{~g}$. The infranatant milk was decanted from the firm cream layer, heated at 90 to $95^{\circ} \mathrm{C}$ for $10 \mathrm{~min}$, and then cooled rapidly. Prolonged or fierce heating was avoided as this caused coagulation of protein. The heat-treated skim milk was then dialysed in the cold with stirring, against five changes (one each morning and evening) of $12 \frac{1}{2}$ litres of deionized water.

The final volume of the dialysed preparation was about $850 \mathrm{ml}$. From this, 1 litre of diluent, containing approximately $2 \%(\mathrm{w} / \mathrm{v})$ milk solids, was made up by adding $36 \mathrm{~g}$ fructose $(200 \mathrm{~mm}), 3.0 \mathrm{~g} \mathrm{NaH} \mathrm{PO}_{2}(19 \mathrm{~mm}), 1.8 \mathrm{~g} \mathrm{NaCl}$ (31 mM), and penicillin and streptomycin $(500,000$ i.u. of each). The final pH was brought to $\mathrm{pH} 7 \cdot 0$ with $\mathrm{NaOH}$.

\section{Criteria of efficacy of washing methods}

It was felt that the best criterion of undamaged spermatozoa (apart from fertility tests which unfortunately were impractical) would be the maintenance of motility. Damage to the membrane allowing coenzymes, substrates and ions to escape would rapidly cause loss of motility, even though no intracellular high molecular weight material were to be lost. Leakage of enzymes would be an indication of greater damage. Thus, the preparations were examined for (a) morphological purity, (b) motility, (c) leakage of enzymes.

(a) Morphological examinations. Samples of sperm suspensions were fixed in formol saline and examined under high-power phase-contrast microscopy for morphological damage to the spermatozoa and for the presence of free cytoplasmic droplets in the sperm preparations.

(b) Motility scores. Samples of sperm suspensions were placed on a warmed microscope slide and examined under low-power magnification in a hot-box maintained at $37^{\circ}$ C. Motility was scored on a scale of 0 to 4 (Emmens, 1947), but $\frac{1}{4}$ grades were frequently assigned.

(c) Leakage estimations. Samples were taken from fractions obtained in the washing procedure (see Text-fig. 1), and spun at $30,000 \mathrm{~g}$ for $25 \mathrm{~min}$ at room temperature or at $4^{\circ} \mathrm{C}$, i.e. the temperature at which the samples had been collected. The $30,000 \mathrm{~g}$ supernatant was then assayed for enzyme activities, 
and, by a knowledge of the volumes and dilution factors involved at each washing stage, the ratios of activity found/activity expected were calculated for each fraction (Table 2). These, together with the total enzyme activity present, were used to assess the amount of leakage occurring at each stage of the washing procedure.

The total enzyme activity present in the final preparations was estimated by assaying a suspension after sonication $\left(\mathrm{P}_{\mathrm{son}}\right)$, and the total soluble enzyme by

TABLE 2

GLUCOSE-PHOSPHATE ISOMERASE AND HEXOKINASE ANALYSES ON THE SUPERNATANTS AND SPERM SUSPENSIONS PREPARED FROM BULL SEMEN, USING THE RINGER, HYPOOSMOTIG AND COOLING METHODS FOR WASHING

\begin{tabular}{|c|c|c|c|c|c|c|c|c|}
\hline \multirow[b]{2}{*}{$\begin{array}{l}\text { Washing } \\
\text { method }\end{array}$} & \multirow[b]{2}{*}{ Fraction } & \multirow[b]{2}{*}{ Dilution } & \multicolumn{3}{|c|}{ Glucose-phosphate isomerase } & \multicolumn{3}{|c|}{ Hexokinase } \\
\hline & & & $\begin{array}{l}\text { Found } \\
\qquad(F)\end{array}$ & $\begin{array}{l}\text { Expected } \\
(E)\end{array}$ & $F / E$ & $\begin{array}{l}\text { Found } \\
(F)\end{array}$ & $\begin{array}{l}\text { Expected } \\
\quad(E)\end{array}$ & $F / E$ \\
\hline \multirow[t]{2}{*}{ Ringer } & $\begin{array}{l}S_{1} \\
S_{2} \\
S_{3} \\
P_{\text {ext }}\end{array}$ & 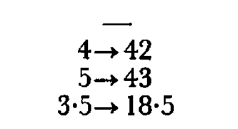 & $\begin{array}{l}15 \cdot 9 \\
1 \cdot 08 \\
0.435 \\
0.85\end{array}$ & $\begin{array}{l}1.51 \\
0.126 \\
0.082\end{array}$ & $\begin{array}{c}\overline{-} \\
0 \cdot 7 \\
3 \cdot 5 \\
10\end{array}$ & $\begin{array}{l}0.28 \\
0.073 \\
0.0515 \\
0.0855\end{array}$ & \begin{tabular}{l}
\multicolumn{1}{c}{$\overline{0.027}$} \\
0.0085 \\
0.00975
\end{tabular} & $\begin{array}{l}\overrightarrow{2 \cdot 7} \\
6 \cdot 1 \\
8 \cdot 8\end{array}$ \\
\hline & $\begin{array}{l}P_{\text {son }} \\
P_{\text {sol }}\end{array}$ & $\begin{aligned} & \text { (Sperm density } \\
= & \left.0.54 \times 10^{9} / \mathrm{ml}\right)\end{aligned}$ & $\begin{array}{l}8 \cdot 3 \\
8 \cdot 25\end{array}$ & & & $\begin{array}{l}1.35 \\
0.66\end{array}$ & & \\
\hline \multirow[t]{2}{*}{$\begin{array}{l}\text { Hypo- } \\
\text { osmotic }\end{array}$} & $\begin{array}{l}S_{1} \\
S_{2} \\
S_{3} \\
P_{c x t}\end{array}$ & $\begin{array}{l}-\underset{40 \cdot 5}{2 \rightarrow 40} \\
2 \rightarrow 43 \\
2 \rightarrow 17 \cdot 5\end{array}$ & $\begin{array}{l}15 \cdot 9 \\
2 \cdot 38 \\
0 \cdot 227 \\
0 \cdot 308\end{array}$ & $\begin{array}{l}0 . \overline{785} \\
0 \cdot 11 \\
0.0275\end{array}$ & $\begin{array}{l}\overline{3 \cdot 0} \\
2 \cdot 1 \\
11\end{array}$ & $\begin{array}{l}0 \cdot 28 \\
0 \cdot 34 \\
0 \cdot 0875 \\
0.0875\end{array}$ & $\begin{array}{l}\overline{0.0138} \\
0.0158 \\
0.01\end{array}$ & $\begin{array}{l}25 \\
5 \cdot 6 \\
8 \cdot 8\end{array}$ \\
\hline & $\begin{array}{l}P_{\text {son }} \\
P_{\text {sol }}\end{array}$ & $\begin{array}{l}\text { (Sperm density } \\
=0.605 \times 10^{9} / \mathrm{ml} \text { ) }\end{array}$ & $\begin{array}{l}6 \cdot 95 \\
7 \cdot 1\end{array}$ & & & $\begin{array}{l}1.47 \\
0.63\end{array}$ & & \\
\hline \multirow[t]{2}{*}{ Cooling } & $\begin{array}{l}S_{1} \\
S_{2} \\
S_{3} \\
P_{\text {ext }}\end{array}$ & $\begin{aligned} 1 & \rightarrow 6 \\
2 & \rightarrow 37 \\
1 \cdot 5 & \rightarrow 36 \cdot 5 \\
1 \cdot 5 & \rightarrow 8 \cdot 5\end{aligned}$ & $\begin{array}{l}2 \cdot 67 \\
0 \cdot 127 \\
0 \cdot 0475 \\
0 \cdot 238\end{array}$ & $\begin{array}{l}0 \cdot \overline{15} \\
0.00515 \\
0.0083\end{array}$ & $\begin{array}{c}- \\
0 \cdot 8 \\
9 \cdot 2 \\
29\end{array}$ & $\frac{\bar{Z}}{0.00965}$ & $=$ & $\begin{array}{l}\text { 二 } \\
-\end{array}$ \\
\hline & $\begin{array}{l}P_{\text {son }} \\
P_{\text {sol }}\end{array}$ & $\begin{array}{c}\text { (Sperm density } \\
=0.50 \times 10^{9} / \mathrm{ml} \text { ) }\end{array}$ & $\begin{array}{l}5 \cdot 38 \\
5 \cdot 43\end{array}$ & & & $\begin{array}{l}1.32 \\
1.04\end{array}$ & & \\
\hline
\end{tabular}

Values are units/ml. 1 unit of enzyme activity transforms $1 \mu \mathrm{mol}$ of substrate/min under the assay conditions $\left(37^{\circ} \mathrm{C}, \mathrm{pH} 7 \cdot 4\right)$.

For details of washing, see Table 1 and Text-fig. 1.

assaying the supernatant after spinning the sonicate at $30,000 \mathrm{~g}$ for $25 \mathrm{~min}$ $\left(\mathbf{P}_{\text {sol }}\right)$.

\section{Enzyme assays}

Samples were assayed for hexokinase and glucose-phosphate isomerase activities. The first enzyme was chosen because of its key position in glycolysis and as possibly representative of a membrane-bound enzyme (Morton, 1968; Harrison, unpublished data), the second as representative of soluble cytoplasmic constituents (de Duve, Wattiaux \& Baudhuin, 1962; Hernandez \& Crane, 1966).

All assays were performed in duplicate at $37^{\circ} \mathrm{C}$ in a volume of $1 \mathrm{ml}$, using a Unicam SP800 recording spectrophotometer, and measuring the increase in optical density at $340 \mathrm{~nm}$ due to the reduction of $\mathrm{NADP}^{+}$in the assay system. 
After representative samples had been shown to give linear activity over a 10-min period, the programming possibilities of the instrument were utilized, and optical density measurements were made automatically before and after an accurately timed 5-min interval; any change was ascribed to a linear rate of reaction. Although not strictly accurate for kinetic work, this method is perfectly satisfactory for most routine purposes (particularly in comparative work), and gives repeatable results. Blank values (i.e. without substrate) were negligible and, since 6-phosphogluconate dehydrogenase was absent (Harrison, unpublished data), it was assumed that $1 \mu \mathrm{mol}$ of $\mathrm{NADP}^{+}$was reduced $/ \mu \mathrm{mol}$ glucose-6-phosphate oxidized during the assays (cf. Vinuela, Salas \& Sols, 1963).

Great care had to be exercised when assaying bull material, particularly when seminal plasma was present, due to the very high nucleotidase activity (see Mann, 1964). This enzyme rapidly destroys the pyridine nucleotide coenzymes, and thus leads to apparently non-linear reduction or oxidation rates in spectrophotometric assays. Careful controls were carried out and initial rates of reaction taken if necessary.

The assay systems used are based upon well known methods (Bergmeyer, 1963); reactions were initiated by addition of samples to the systems. For hexokinase, the final concentrations in the cuvette were $100 \mathrm{~mm}$-tris/ $\mathrm{HCl}$ buffer ( $\mathrm{pH} 7.4$ at $37^{\circ} \mathrm{C}$ ), $1 \mathrm{~mm}$-EDTA, $1 \mathrm{~mm}$-2-mercaptoethanol, $10 \mathrm{~mm}$ $\mathrm{MgCl}_{2}, 2.5 \mathrm{~mm}$-ATP (neutralized), $1 \mathrm{~mm}$-glucose, $0.5 \mathrm{~mm}-\mathrm{NADP}^{+}$, and $2 \mu \mathrm{g} / \mathrm{ml}$ crystalline glucose-6-phosphate dehydrogenase (0.56 units). For glucosephosphate isomerase, the final concentrations in the cuvette were $100 \mathrm{~mm}$ tris/ $\mathrm{HCl}$ buffer $\left(\mathrm{pH} 7.4\right.$ at $\left.37^{\circ} \mathrm{C}\right), 1 \mathrm{~mm}$-EDTA, 1 mM-2-mercaptoethanol, $10 \mathrm{~mm}_{-} \mathrm{MgCl}_{2}, 1 \mathrm{~mm}$-fructose-6-phosphate, $0.5 \mathrm{~mm}-\mathrm{NADP}^{+}$and $2 \mu \mathrm{g} / \mathrm{ml}$ crystalline glucose-6-phosphate dehydrogenase (0.56 units).

\section{Sperm density}

Sperm density estimations were performed by measuring the absorbance of suitably diluted samples in formol saline on a Hilger Spekker absorptiometer and calculating the relevant sperm density from a standard curve (Dott, 1960).

\section{Chemicals}

All chemicals were 'Analar' grade where possible and solutions for analytical use were made up in distilled, deionized water. High purity deionized water was used for all other solutions. Biochemicals, coenzymes, 2-mercaptoethanol and tris were obtained from Sigma Chemical Co. (London) Ltd, and crystalline glucose-6-phosphate dehydrogenase from Boehringer Corpn, London, Ltd.

\section{RESULTS}

Table 2 gives the actual and expected results of analyses for glucose-phosphate isomerase and hexokinase made on the supernatants $\left(S_{1}, S_{2}, S_{3}\right)$ from a sample of bull semen during the washing procedure outlined in Text-fig. 1 using the Ringer, hypo-osmotic and cooling methods. Values for the final sperm suspensions before $\left(\mathrm{P}_{\text {ext }}\right)$ and after sonication $\left(\mathrm{P}_{\text {son }}\right.$ and $\left.\mathrm{P}_{\text {sol }}\right)$ are also given. 

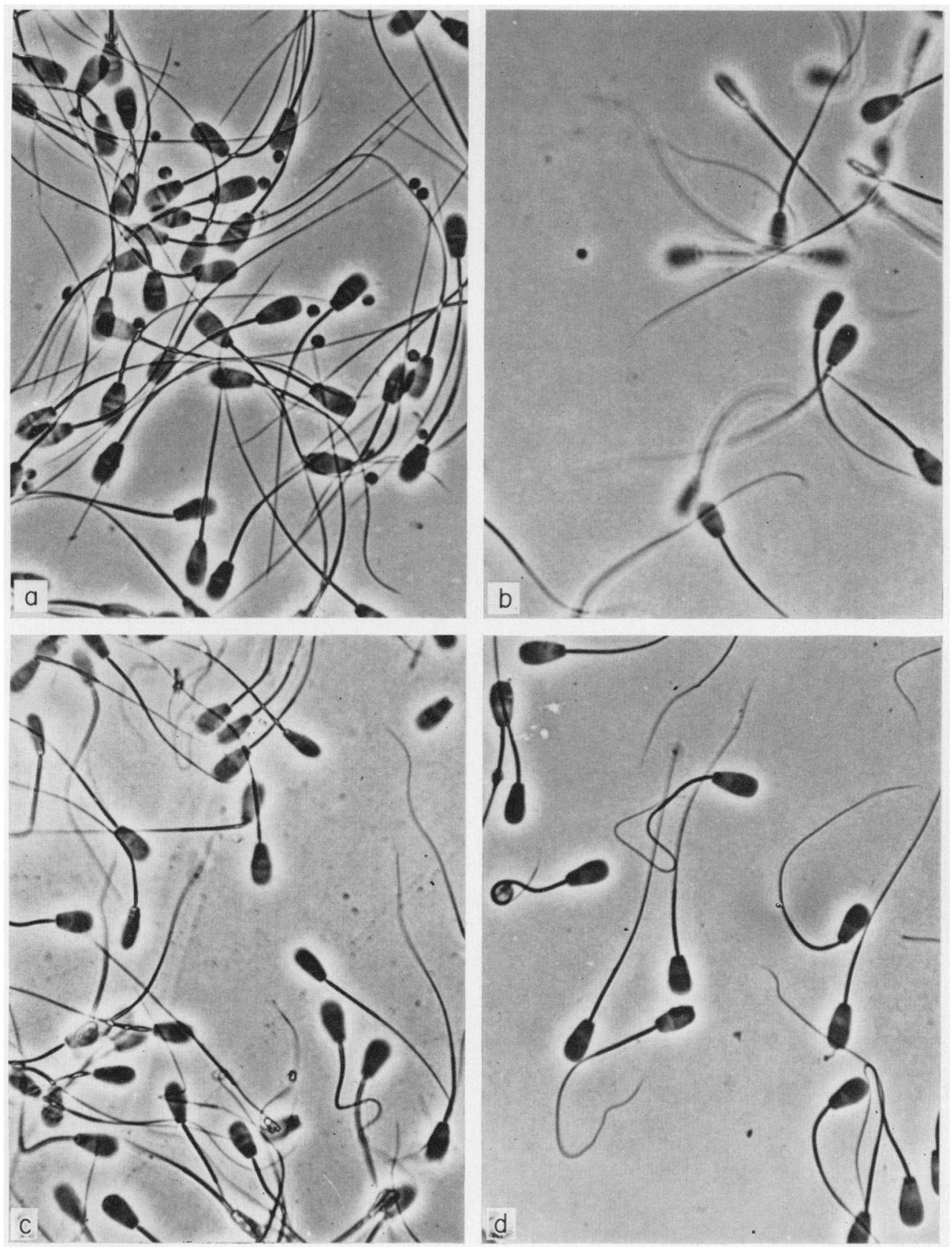

(a) Bull semen. (b) Bull spermatozoa washed by Ringer method. (c) Buil spermatozoa washed by hypo-osmotic method. (d) Bull spermatozoa washed by cooling method. All photographed under phase-contrast, $\times 6 \overline{5} 0$. 
PLATE 2
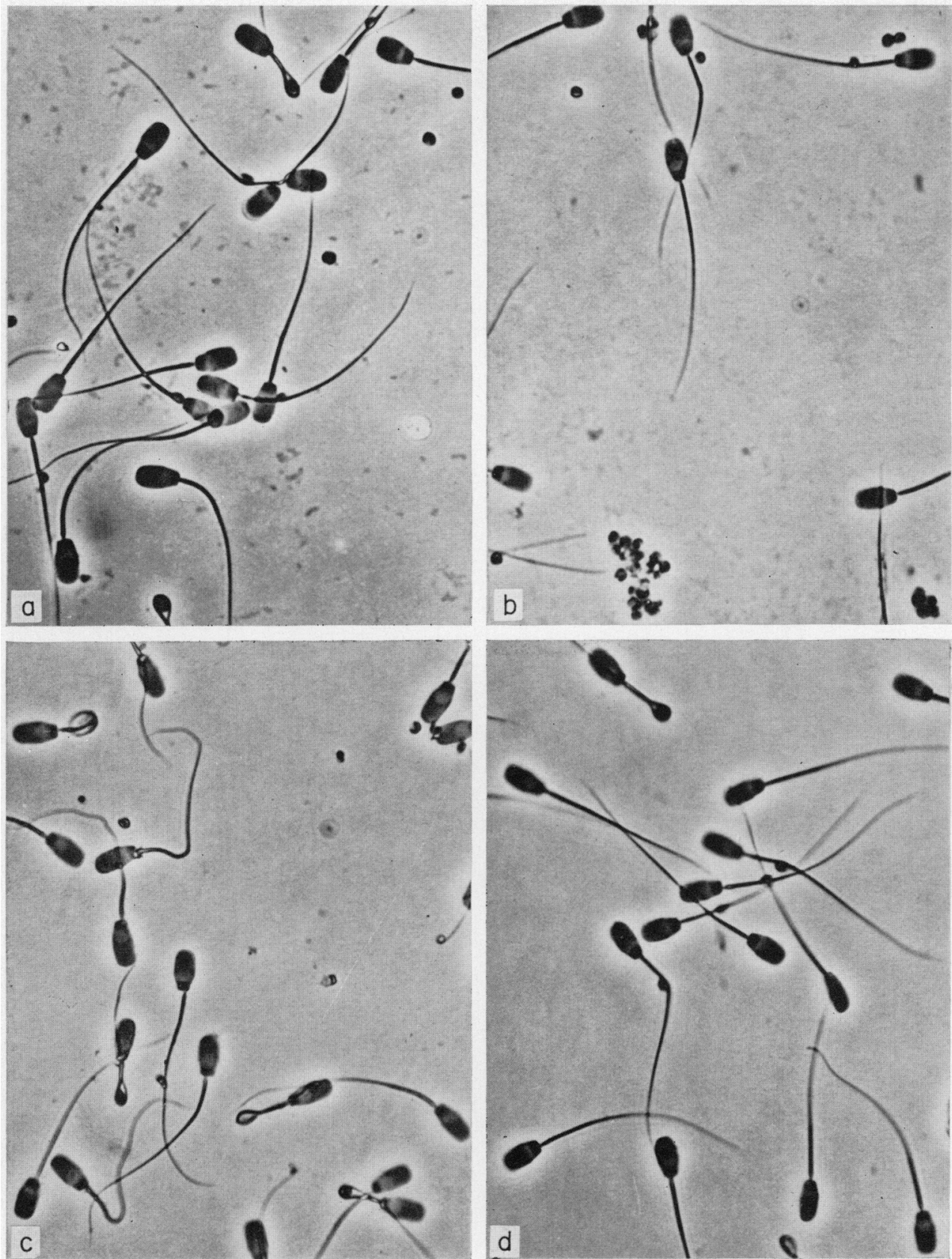

(a) Boar semen. (b) Boar spermatozoa washed by Ringer method. (c) Boar spermatozoa washed by hypo-osmotic method. (d) Boar spermatozoa washed by cooling method. All photographed under phase-contrast, $\times 650$. 
From these results, which are typical of several similar experiments, a biochemical evaluation could be made of the different washing methods.

The essential results of enzyme analyses on the final suspensions of washed bull, boar and ram spermatozoa are shown in Table 3, together with data on the extent of contamination by free-lying cytoplasmic droplets and data on sperm motility. These are the mean of two experiments for each species for each method. All analyses were performed in duplicate.

\section{Purity of sperm suspensions}

Photographs of suspensions of washed bull and boar spermatozoa are shown in Plates 1 and 2; washed ram sperm suspensions had a similar appearance to those of bull.

Free cytoplasmic droplets could not be removed entirely from the sperm suspensions by the Ringer method. The droplets could generally be removed to a large extent from bull sperm suspensions and to a lesser extent from ram sperm suspensions, but the results were variable. After ejaculation, the droplets in boar semen tended to agglomerate into clumps of as many as twenty or more particles (Plate $2 b$ ). These always sedimented with the spermatozoa and could not be removed.

When bull semen was diluted rapidly with HOP, many droplets disappeared and the rest were fragmented. Since the spermatozoa were immobilized, the contaminating fragments could be removed by differential centrifugation. Similar results were obtained with ram semen (although fragmentation of the droplets was less complete), whereas the droplets and their agglomerates in boar semen appeared much more refractory to HOP than droplets from ram and bull and did not fragment to any great extent; moreover, washing did not dissolve the agglomerates, which always sedimented with the spermatozoa even under low centrifugal force. The hypo-osmotic effect was not specific for phosphate buffers: similar results were obtained with $50 \mathrm{~mm}$-tris, though $100 \mathrm{~mm}$-tris or $100 \mathrm{~mm}$-phosphate had little effect.

The cooling method was successful: bull, boar and ram spermatozoa could be reversibly immobilized, then sedimented under low centrifugal force, and the intact droplets removed in the supernatant. The agglomerates of droplets in boar semen, under these conditions of dilution with milk diluent and subsequent slow cooling, were found next morning to have separated into single intact particles again. This was inexplicable but fortunate.

\section{Motility}

The motility of spermatozoa washed either by the Ringer or the cooling

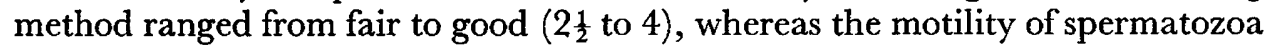
washed using the hypo-osmotic method was, of course, very low ( $\frac{1}{2}$ to 1 ). However, the time required for boar spermatozoa to recover their motility after storage at $4^{\circ} \mathrm{C}$ overnight was very variable and incubation for up to 30 min at $37^{\circ} \mathrm{C}$ was frequently needed. It was also found that although various iso-osmotic media could be used to wash ram, bull and boar spermatozoa using the cooling method, motility was best when the spermatozoa were finally resuspended in milk diluent. Krebs-Ringer-fructose-phosphate medium was 


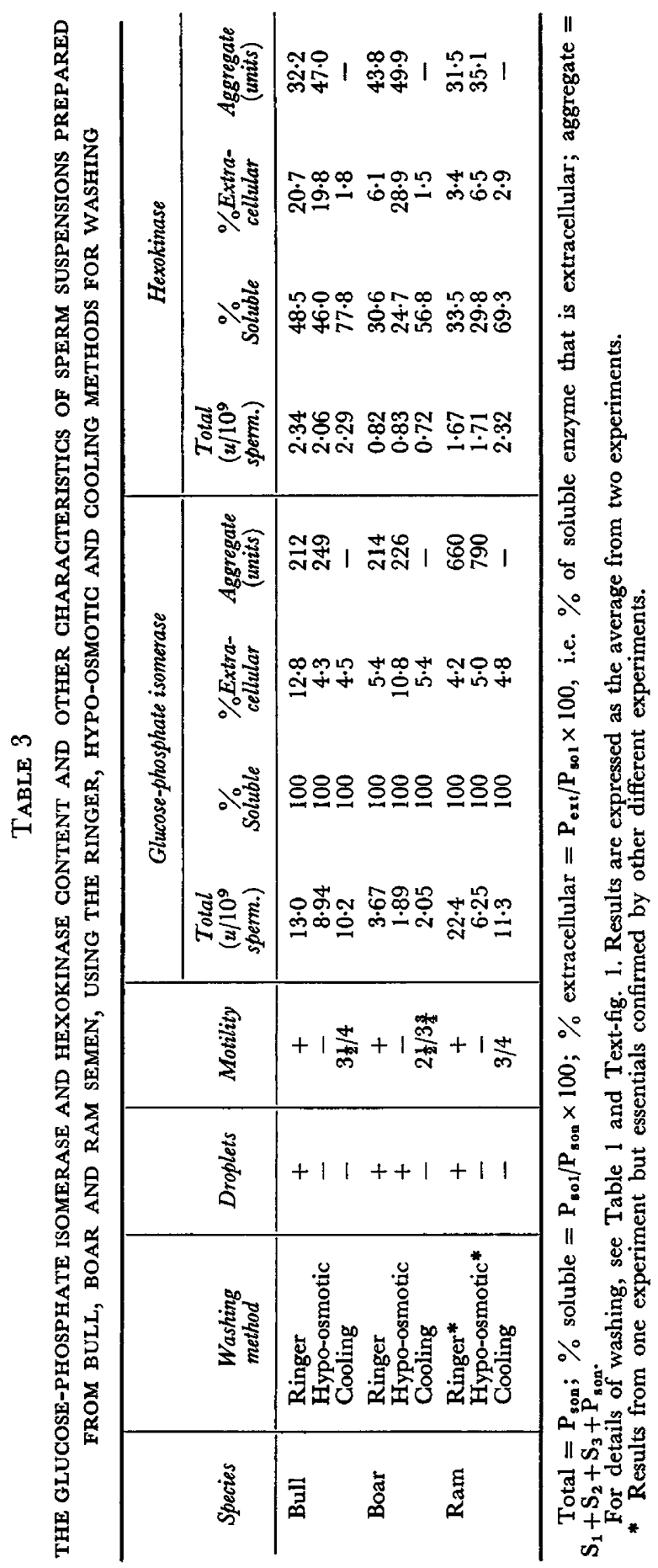


clearly inferior to the latter as a final suspension medium, although it was satisfactory as a wash medium. Text-figure 2 shows an example of these observations, which have been published in greater detail elsewhere (White \& Harrison, 1971).

\section{Leakage}

The use of glucose-phosphate isomerase as a marker for enzyme leakage proved very useful. Firstly, the enzyme appeared to be readily released, even under apparently mild conditions; secondly, its high activity in spermatozoa made for great sensitivity; thirdly, its presence in seminal plasma enabled

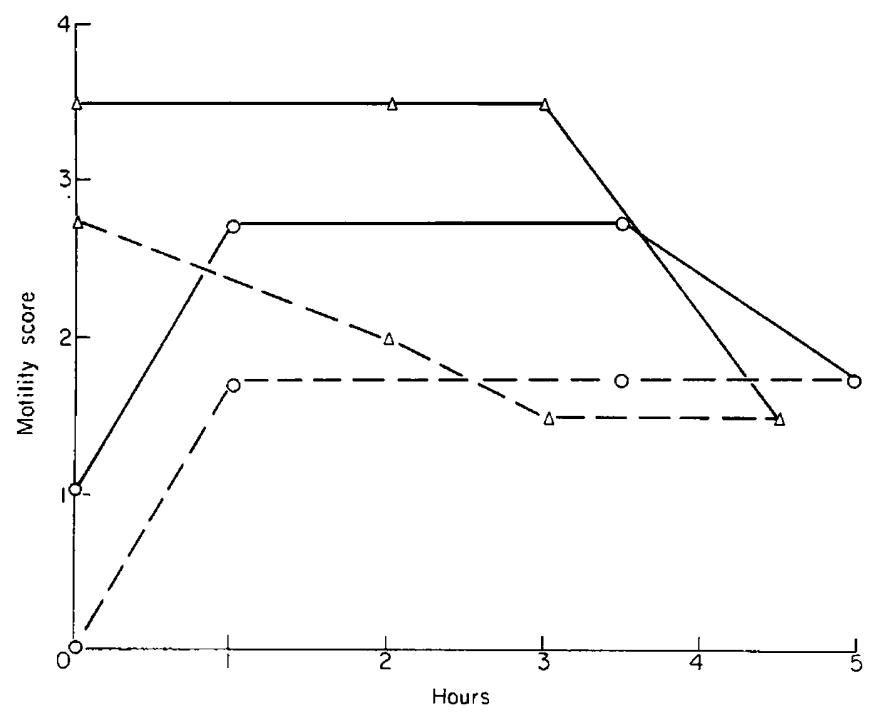

TEXT-FIG. 2. Effect of final resuspension medium on motility of spermatozoa washed by cooling method. Semen was washed by the cooling method using RFP as the wash medium. Samples from each final pellet were resuspended either in milk diluent $(-\longrightarrow)$ or in RFP (-- ) and incubated at $37^{\circ} \mathrm{C} . \Delta$, Ram spermatozoa; $O$, boar spermatozoa.

checks to be made on the efficiency of the washing procedures when leakage was minimal. Hexokinase activity measurements gave less unequivocal results for various reasons (see Discussion).

Table 3 shows that, as judged by the extent of leakage in the final sperm suspension (i.e. the percentage extracellular enzyme), the cooling method was, in general, again the best. The higher percentages of soluble hexokinase in the results for the cooling method were almost certainly due to the membranebound nature of the enzyme (see Discussion) which lowered its sedimentation rate in the higher density of the sucrose wash medium.

The analyses on the supernatants (Table 2) showed that leakage of glucosephosphate isomerase and hexokinase occurred to a variable extent during washing in all of the three methods tested. If leakage did not occur, the maximum value of the $F / E$ ratio would be 1 , whereas ratios greater than this indicate leakage. (In calculating the expected values for the enzyme concentration of the supernatants, the actual sperm volume has been ignored. The true expected values are, therefore, slightly lower than indicated.) 
Diluting the sperm suspension from the first centrifugation with HOP caused a sudden and great increase in the activity of glucose-phosphate isomerase and hexokinase in the supernatants. Hypo-osmotic shock apart, leakage appeared to be associated largely with manipulative procedures, and particularly with the vigour of resuspending centrifuged pellets. This was also true of samples subjected to hypo-osmotic shock; after the initial increase in enzyme activity in the supernatant, further washing in HOP did not lead to further leakage more than could be accounted for by manipulation using control samples in RFP. Leakage during the actual washing procedures was lower in the cooling method than in either of the others, presumably due to the loose packing and easy resuspension of the pellets after centrifugation.

Incubation of final suspensions of bull and boar spermatozoa washed in

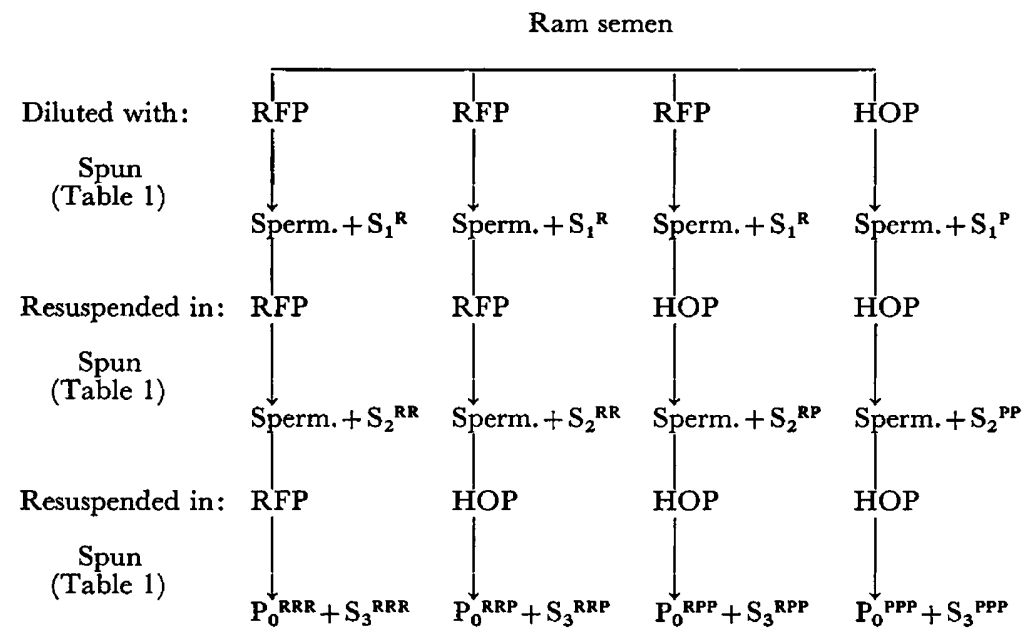

TEXT-FIG. 3. Design of experiment to test leakage after hypo-osmotic shock of ram spermatozoa at different stages of washing. All $P_{0}$ fractions were finally resuspended again in the same media as for the final wash and, together with all the wash supernatants, were analysed in the usual way (Text-fig. 1 , and Materials and Methods).

RFP or in HOP (data not given) showed that there was little increase in leakage of glucose-phosphate isomerase with time, thus tending to confirm the hypothesis that manipulation was responsible for leakage of this enzyme. However, leakage of hexokinase was clearly time-dependent, particularly in samples which had been subjected to hypo-osmotic shock, and was considerable when calculated as a percentage of the total soluble activity present (30 to $40 \%$ in $3 \mathrm{hr}$ ). Thus, a clear-cut discrepancy existed between the behaviour of the two enzymes.

In another experiment, a collection of ram semen was divided into four. One sample was diluted with RFP and washed twice with RFP; a second was diluted with RFP, washed once with RFP, and then once with HOP; a third was diluted with RFP, and washed twice with HOP; a fourth semen sample was diluted and then washed twice with HOP only (see Text-fig. 3 for scheme). Glucose-phosphate isomerase and hexokinase were measured in the various supernatants. Essentially, in this experiment, the spermatozoa were subjected to 
hypo-osmotic shock after they had been progressively freed from other seminal contaminants. It had been expected that the increased leakage of the enzymes due to shock would be constant at each stage and merely dependent upon the total number of spermatozoa in the sample. However, this was not the case; the leakage (figures not given) was largely proportional to the amount of seminal contamination (i.e. the enzyme activity in $\mathrm{S}_{1}{ }^{\mathrm{P}}>\mathrm{S}_{2}{ }^{\mathrm{RP}}>\mathrm{S}_{3}{ }^{\mathrm{RRP}}$ ), while the enzyme contents in the three final shocked sperm suspensions (i.e. $\mathbf{P}_{0}{ }^{\text {RRP }}, \mathbf{P}_{0}{ }^{\text {RPP }}$ and $\mathbf{P}_{0}{ }^{\mathrm{PPP}}$ ) were similar, bearing no relation to the amount of leakage found to occur during washing. The glucose-phosphate isomerase content in the fourth, unshocked, sperm suspension $\left(\mathrm{P}_{0}{ }^{\mathrm{RRR}}\right)$ was higher; however, there were many droplets present.

By performing the RFP and HOP washing experiments on split samples of semen, it was possible to estimate the total enzyme activities accounted for in all fractions (i.e. $S_{1}, S_{2}, S_{3}$ and $P_{\text {son }}$ ). In every pair of experiments, the total was higher for the HOP samples subjected to hypo-osmotic shock than for the RFP controls (Table 3): enzyme activity had appeared from 'nowhere'. The only fraction not accounted for in these estimations was the particulate matter in the washes. This matter consisted largely of cytoplasmic droplets.

\section{DISGUSSION}

\section{Leakage of enzymes during washing}

The appearance of glucose-phosphate isomerase and hexokinase in the extracellular fluid during the washing of bull, boar and ram spermatozoa was demonstrated clearly in all three washing methods studied, and it would seem that these enzymes leak from the spermatozoa during washing. However, three observations suggest that the spermatozoa themselves are not the only source of the enzymes and that leakage also occurs from the cytoplasmic droplets in the sperm suspensions: the first of these is the correlation between leakage after hypo-osmotic shock and the degree of contaminating seminal plasma containing cytoplasmic droplets; the second is the presence of latent enzyme activity as well as particulate matter (mostly droplets) in the washings; the third is the correlation between leakage and damage to droplets-hypoosmotic shock which fragmented ram and bull droplets caused extensive leakage when droplets were present, whereas when the droplets were removed intact during washing by the cooling method, leakage was low.

Dott \& Dingle (1968) have demonstrated the fragility of cytoplasmic droplets, and have also shown some lysosomal enzymes to be common to both spermatozoa and droplets; moreover, the cytoplasmic droplet originates from the sperm flagellum, in which the glycolytic enzymes are thought to be located (see Bishop \& Walton, 1960; Mann, 1964). If the cytoplasmic droplets from ram, bull and boar spermatozoa contain glycolytic enzymes, are variably fragile and leak their contents on hypo-osmotic shock, then the observed results are explained. In fact, subsequent work proved these suppositions to be correct (Harrison \& White, 1969; Harrison \& White, in preparation), and the results reported here will be interpreted accordingly.

Leakage of glycolytic enzymes during hypo-osmotic shock of semen was 
largely due to the release of cytoplasmic droplet contents, though the spermatozoa may have contributed a little. Leakage during resuspension and other manipulations was also largely due to damage of droplets. The correlation of leakage during hypo-osmotic shock with the contamination of the spermatozoa by seminal plasma was due to the presence of droplets, and the appearance of enzyme from 'nowhere' in hypo-osmotically shocked preparations again due to the droplet contributions. The different amounts of leakage found when washing ram, bull and boar spermatozoa in RFP correlated with the different species fragility of the droplets and the ease with which their enzyme contents were released.

The observations on hexokinase leakage are more complex, but further work (Harrison, unpublished observations) has suggested that this enzyme in ram, bull and boar spermatozoa may be partly associated with outer membranes and partly bound to interior structures. Since the source of sperm and droplet enzymes is common, it seems possible that the hexokinase in cytoplasmic droplets is also associated with membranes. When release of glucose-phosphate isomerase from droplets was complete, as under conditions of hypo-osmotic shock, the progressive fragmentation of membranes from these preparations led to continued 'leakage' of hexokinase with no concurrent leakage of glucose-phosphate isomerase, after the initial sudden leakage of both enzymes. This explains the results of the incubation experiment where damaged droplets were present in suspensions of bull and boar spermatozoa washed in RFP and HOP and the discrepancy between the extracellular activities in Table 3. The much lower 'leakage' of hexokinase during washing by the cooling method was due partly to the absence of droplets and droplet fragments from these preparations, but also to the mildness of the manipulations which obviated extensive membrane damage.

The discrepancy between the behaviour of the two enzymes illustrates a problem encountered in studies on enzyme leakage: generalizations cannot be made from the behaviour of one enzyme because results will depend upon the state of the enzyme (i.e. bound or free), and its location within the cell. More illuminating observations may be made using several enzymes as markers; certain enzymes may be more suitable than others and due consideration must be given to the final choice. Although the use of glucose-phosphate isomerase as a marker for enzyme leakage may have more general applications than to semen alone, due to its solubility and association with cytoplasm (de Duve et al., 1962; Hernandez \& Crane, 1966), it must be remembered that the results reported here are strictly only true for this enzyme and at best to soluble cytoplasmic constituents. They cannot be applied to any other spermatozoal substances.

\section{Methods of washing spermatozoa}

The presence of glycolytic enzymes in cytoplasmic droplets as well as in spermatozoa (Harrison \& White, in preparation) underlines the need to remove droplets from sperm preparations, particularly for biochemical studies. Although the cooling method has drawbacks, it is the only washing method we have tried which will yield a preparation of spermatozoa without free-lying droplets from all three species. (In most ejaculates, particularly those from boar, 
there will be some spermatozoa with droplets still attached to the tail structure - see, for example, Plate $2 \mathrm{~d}$-and these cannot be removed by washing.)

While it may not be original in principle or the only method possible, the cooling method has the following advantages. Firstly, cooling in an optimal diluent enables semen to be stored with the maintenance of potential motility for over a week, possibly also with the maintenance of fertility (Maule, 1962). Secondly, washing at low temperatures enables cytoplasmic droplets and other contaminants to be removed from the temporarily immotile spermatozoa by slow differential centrifugation. This avoids tight packing of the sperm pellet and damage during resuspension is reduced. The dissolution of droplet aggregates in boar semen during slow cooling seems unique and is apparently the only way of removing them. Thirdly, the use of sucrose wash media increases the relative difference in buoyant densities between droplets and spermatozoa and thus improves the efficiency of the washing process. The use of very simple media does not appear to harm spermatozoa or droplets at low temperatures, and enables suspensions to be made in any solution at will. Fourthly, the diluents and wash media are easily prepared, economical and highly defined, and contain few possible contaminating substances-most enzymes in the milk are destroyed by the heat treatment. The method is therefore practical, effective and convenient. The actual time spent on the manipulations is short and the washing procedures rapid.

The disadvantages of the cooling method and of washing in general are associated with the 'cold-shock' and 'dilution' phenomena. Both cooling and dilution are detrimental to spermatozoa, even in optimal diluents (Maule, 1962), although the spermatozoa of some species may be largely protected against damage by including in the medium high molecular weight substances usually of a phospho-lipo-protein nature (Emmens \& Blackshaw, 1956). The damage is probably due to stripping of the lipo-protein coating which envelops the spermatozoon and prevent loss of essential molecules; protective agents are considered to act by replacing this material.

In this study, we have suggested a method of washing spermatozoa which we feel offers the best results and the fewest drawbacks, but we emphasize that there is no single solution to the general problem. Each problem will demand a special solution, although the general principles are universally applicable.

\section{ACKNOWLEDGMENTS}

We are grateful to Professor T. Mann for his helpful advice and to $\mathrm{Dr}$ H. M. Dott and Mr I. Wilmut for collecting semen. One of us (I.G.W.) also wishes to thank the Wellcome Foundation for a travel grant and the Population Council for a fellowship.

\section{REFERENCES}

BAKER, J. R. (1931) An improved fluid for mammalian sperm-suspensions. Q. Fl exp. Physiol. 21, 139. Bergmeyer, H. U. (Ed.) (1963) Methods of enzymatic analysis. Academic Press, New York and London. Bishop, M. W. H. \& WALton, A. (1960) Metabolism and motility of mammalian spermatozoa. In: Marshall's Physiology of Reproduction, 3rd edn, Vol. 1, Pt 2, p. 264. Ed. A. S. Parkes. Longmans Green, London. 
de Duve, C., Wattiaux, R. \& Baudhuin, P. (1962) Distribution of enzymes between subcellular fractions in animal tissues. Adv. Enzymol. 24, 291.

Dotт, H. M. (1960) Physiology of mammalian spermatozoa. Ph.D. thesis, University of Cambridge.

Dotr, H. M. \& DiNGLe, J. T. (1968) Distribution of lysosomal enzymes in the spermatozoa and cytoplasmic droplets of bull and ram. Expl Cell Res. 52, 523.

DU Mesnil du Buisson, F. (1956) Conservation du sperme de verrat après dilution et maintien de son pouvoir fécondant. Annls Zootech. 3, 195.

Emmens, C. W. (1947) The motility and viability of rabbit spermatozoa at different hydrogen ion concentrations. 7. Physiol., Lond. 106, 471.

Emmens, C. W. \& Blackshaw, A. W. (1956) Artificial insemination. Physiol. Rev. 36, 277.

Harrison, R. A. P. \& White, I. G. (1969) Distribution and behaviour of some glycolytic enzymes in spermatozoa and cytoplasmic droplets from mammalian semen. Biochem. F. 111, 36p.

Hernandez, A. \& Crane, R. K. (1966) Association of heart hexokinase with subcellular structure. Archs Biochem. Biophys. 113, 223.

Hoskins, D. D. \& Patterson, D. L. (1967) Prevention of coagulum formation with recovery of motile spermatozoa from rhesus monkey semen. F. Reprod. Fert. 13, 337.

LAPWOOD, K. R. (1968) Studies of diluents for, and the dilution and insemination of ram spermatozoa. Ph.D. thesis, University of Sydney.

MANN, T. (1964) The biochemistry of semen and of the male reproductive tract. Methuen, London.

Maule, J. P. (Ed.), (1962) The semen of animals and artificial insemination. Commonwealth Agricultural Bureaux, Farnham Royal, Bucks.

Morton, B. E. (1968) A disruption and fractionation of bovine epididymal spermatozoa. F. Reprod. Fert. $15,113$.

Quinn, P. J. \& Whire, I. G. (1969) Osmotic shock of ram spermatozoa. F. Reprod. Fert. 18, 375.

RiKmenspoes, R. (1965) The inhibition by amytal of respiration and motility of bull spermatozoa. Expl Cell Res. 37, 312.

Salisbury, G. W. \& Graves, G. N. (1963) Substrate-free epididymal-like bovine spermatozoa. 7 . Reprod. Fert. 6, 351.

Vinuela, E., Salas, M. \& Sols, A. (1963) Glucokinase and hexokinase in liver in relation to glycogen synthesis. F. biol. Chem. 238, PC1175.

Wales, R. G. \& Humphries, E. J. (1969) The intracellular accumulation of metabolites by ram spermatozoa during incubation in the presence of exogenous fructose. Aust. 7. biol. Sci. 22, 1005.

Whrre, I. G. (1953) Metabolic studies of washed and diluted ram and bull spermatozoa. Aust. F. biol. Sci. 6, 706.

WhITE, I. G. \& HaRRISON, R. A. P. (1971) Observations on the survival of washed boar spermatozoa in different media. F. Reprod. Fert. 26, 129. 